\title{
Nonlinear Control Systems E-learning Course Support
}

\author{
http://dx.doi.org/10.3991/ijoe.v9i1.2408 \\ P. Ťapák ${ }^{1}$, M. Huba ${ }^{1}$ and I. Masár ${ }^{2}$ \\ ${ }^{1}$ FEI STU in Bratislava, Bratislava, Slovakia \\ 2 Process Control Engineering Group, Process Control Engineering, Hagen, Germany
}

\begin{abstract}
The paper presents the course on nonlinear control systems created in cooperation of the Institute of Control and Industrial Informatics of the Faculty of Electrical Engineering and Information Technology of the Slovak University of Technology in Bratislava with the Institute PRT/MI, Fernuniversitat in Hagen. The differences in real experiments utilization in the course considering distance and regular education are discussed.
\end{abstract}

Index Terms-non-linear systems, real experiment, disturbance observer.

\section{INTRODUCTION}

For long decades, in education of the theory of automatic control, simulations represented the only type of activities enabling learning by experimenting. This approach is still suitable for e-learning as well. However there is a strong difference between the theory and modeling based simulations and real time experimenting in practice - at least from that point that the students have to be able to deal with the practical problems in the relevant authentic environment as well. This is recently respected by a strong effort focused world-wide on remote laboratories [1]-[6], [8]-[15].

This paper discusses the support for learning by experimenting within the course on nonlinear control created in a broader international cooperation. Several plants have been developed at Institute of Control and Industrial Informatics in Bratislava [8], [15], [16] to provide the students with the real-time experiment to let them gain some experience of the applying the theory on the real problem . The philosophy of the "learning by doing" or of the "experiential learning" makes relaxed and stimulating course atmosphere, in which students are generally more motivated to commit themselves actively to the control design and its verification. It is not very difficult to manipulate the plants we use in the course using a linear control theory as well. The challenge was to develop the course with the set of experiments to let the students see the improvements in control performance when using more sophisticated, nonlinear, control algorithms.

\section{REAL-TIME EXPERIMENT}

To enable each student to work actively and individually in a quasi-authentic framework with real time experiments, we need to have numerous plant models that guarantee: clear physical "visibility" of the controlled dynamics, time constants in the range ms-few minutes, safety manipulation, reasonable price, availability of sensors and actuators, easy maintenance, connectivity to

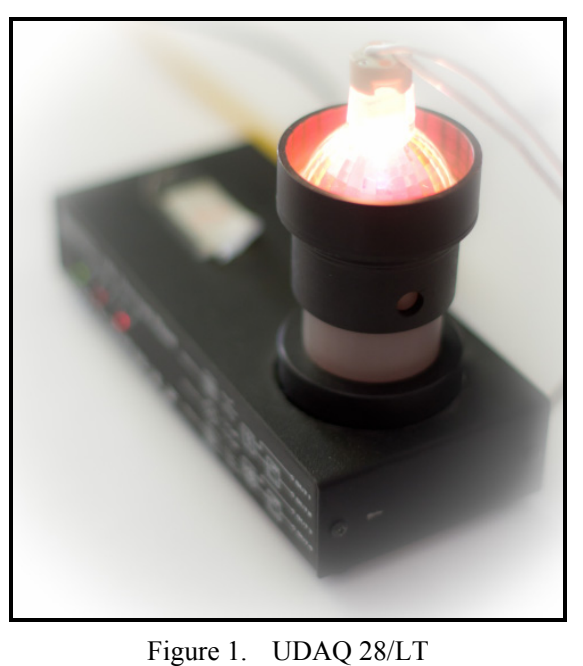

standard computers without special converter cards, suitable for remote experiment via internet, plants with different level of "the control difficulty", plants offering broader spectrum of dynamics to be controlled.

As a typical representative of a plant having all required features we can mention the thermo-optical plant (Fig.1) [7], [9], [15]. This product of several decades of development offers measurement of eight process variables (controlled temperature and its filtered value, ambient temperature, controlled light intensity, its filtered value and its derivative, the ventilator speed of rotation and its motor current). The temperature and the light intensity control channels are interconnected by 3 manipulated variables: the bulb voltage (the heat $\&$ light source), the light-diode voltage (the light source) and the ventilator voltage (the system cooling). The plant can be easily connected to standard computers via USB, when it enables to work with the sampling periods $40-50 \mathrm{~ms}$ and larger. Within the Matlab/Simulink scheme the plant is represented as a single block, limiting use of costly and complicated software package for the real time control. So, the usual process-computer communication based on standard converter cards (that is also supported) is necessary just for more demanding applications requiring higher sampling frequencies.

Two approaches in making the real experiments available were used. At Institute of Control and Industrial Informatics FEI STU in Bratislava there was the way of quantity used. The students are allowed to take the plants home to make experiments. At the Fernuniversitat in Hagen the remote experiment strategy is going to be implemented. 
PAPER

NONLINEAR CONTROL SYSTEMS E-LEARNING COURSE SUPPORT

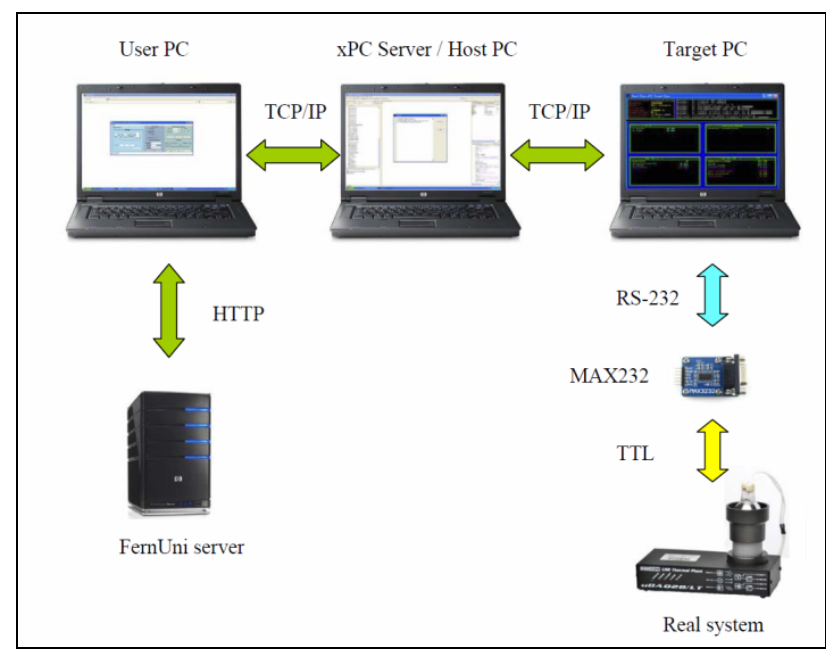

Figure 2. Remote controlled laboratory using xPC Target

\section{SOME COMMON MistaKeS}

The remote laboratory was designed in accordance with our concept of a flexible, easy re-configurable remote laboratory [12]. The control algorithms are designed and implemented by the Matlab/Simulink software package with Real-Time Workshop and xPC Target Toolbox. These tools are able to automatically generate stand-alone real-time applications from Simulink models that run on the so-called Target PC, while their development is carried out on separate host computer (Host PC). The Target PC is based on a special real-time operating system and it communicates with the Host PC through serial link or network connection. Through this connection it is possible to operate the Target PC (load/start/stop application, change algorithm parameters, trace signals) completely by the Host PC (from the Matlab command line or directly from the Simulink model).

On the server side of the experiments we use several components which control the Internet access to the lab and the course of the experiment and exchange the data between the user and the lab. For the tele-operation of the lab we designed xPC Target Server (Fig. 2). It performs a basic control of the Target PC (restart, opening/closing of the communication port), downloads a real-time application to the real-time target and controls its execution. In addition, it is used for setting of the controller parameters and signal tracing. Moreover, the xPC Server communicates with the client components.

Client components are dedicated to experimental flow control and data visualization. The communication with all servers involved is based on the TCP protocol and can be handled by standard Web-Browsers. All client components are implemented as JAVA-applets. Thereby, a comfortable and easy to operate user interface is created (Fig. 7). The main requirement on the clients side can thus be reduces to standard Web-browser without additional software.

\section{ASSINGNEMENT EXAMPLE}

In this chapter the example of assignment where students can see the performance improvement achieved by nonlinear control will be presented. The filtered light channel is used to practice the control strategies on real plant. The optical channel used in following experiments consists of the light intensity produced by bulb measured by a photodiode and filtered by an analogue low pass filter with the time constant about 20s. The first order linear model

$$
S(s)=\frac{Y(s)}{U(s)}=\frac{K_{1}}{T_{1} s+1} e^{-T_{d} s}=\frac{K_{s}}{s+a} e^{-T_{d} s}
$$

will be used for plant approximation.

The tasks the students should make in this assignment are:

- Pant identification

- Light intensity control using linear PI controller with or without antiwindup. They have to achieve fast transients without overshooting making several setpoint steps and input disturbance steps.

- Light intensity control using a defined nonlinear controller making the same setpoint and disturbance steps to be able to compare the results.

- Try to achieve better performance using linear PI controller with or without antiwindup.

- Make conlusion

TABLE I.

SYSTEM PARAMETERS

\begin{tabular}{|c|c|c|c|c|}
\hline \multicolumn{5}{|c|}{ System parameters in various working points covering the whole } \\
working range
\end{tabular}

The identification can be made by making a sequence of input steps. In each working point the parameters of linear transfer function can be obtained. The following table shows the system parameters evaluated for 10 input steps. The students can see that the process gain depends on the operating point. They have to deal with this nonlinearity at first by trial and error approach. After few attempts using minimum average or maximum value of the process gain for PI controller tuning they should be able to achieve desired control quality.

In the next step they have choose maximum values of process gain and the process time constant for the tuning of the non-linear PI controller. Making the same setpoint and disturbance steps they can compare the controller performance. 
PAPER

NonlineAr CONTROL SySTEMS E-LEARNING COURSE SupPorT

Following figures show examples of possible experiment results. In Fig. 3 one can see a detail of the setpoint step transients. There is obvious that the linear PI controller suffers from windup effect and produces large overshooting. The linear PI controller with anti-windup gives fast transients without overshooting, but the nonlinear PI controller gives faster transients. Fig.4 shows the corresponding control signals. The non-linear controller and linear PI controller with antiwindup structure give the control signal of desired shape with one interval at the saturation with the exponential transient to the new steady state.

The Figs. 5-6 show the detail of system output and the control signal for upward and downward disturbance rejection. There is obvious that the nonlinear controller gives the fastest disturbance rejection. The control signal transients show that none of the controllers attacks the saturation limits. The students should learn that even a very simple plant, first order stable system, can be difficult to control when the control signal saturation has to be taken into account. The change in the controller structure is necessary when the fast transients without overshooting and quick disturbance rejection are needed.

\section{COURSE Structure}

The course uses LMS Moodle, where the study materials, assignments and the test are available. So the students are supported by: permanently updated electronic course materials containing Matlab/Simulink programmes for simulation, design and control experiments, computer tests for self-evaluation, etc., physical models of real plants to be controlled (Fig.1) that are either sent or given to each student or made accessible via Internet, face-toface workshops (if required by students) and tutors.

\section{CONCLUSIONS}

Huge amount of experiments carried out by students produces not only skills in experimenting for both students and teachers but also many questions that have to be answered from the theoretical point of views. This, together with cooperation with several partner universities has a stimulating effect not only on education, but simultaneously on the carried out research activities, too.

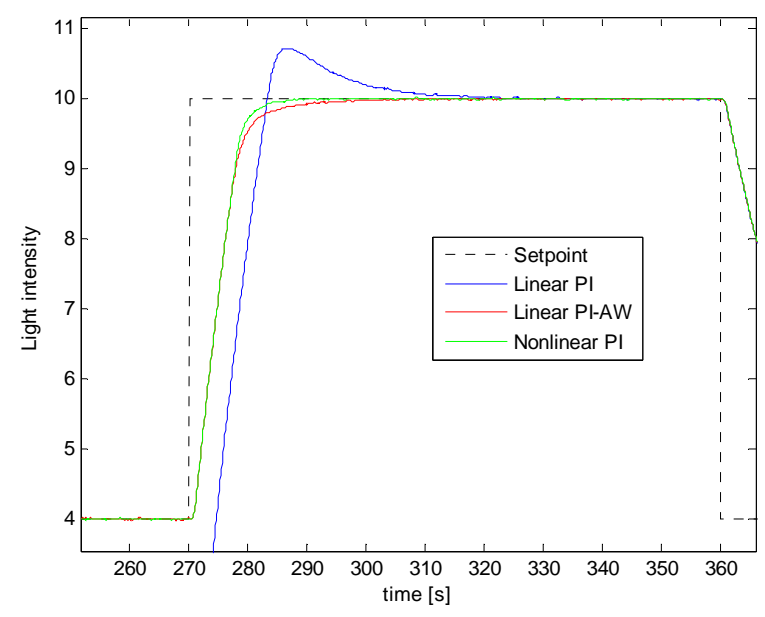

Figure 3. Control quality comparison - System output

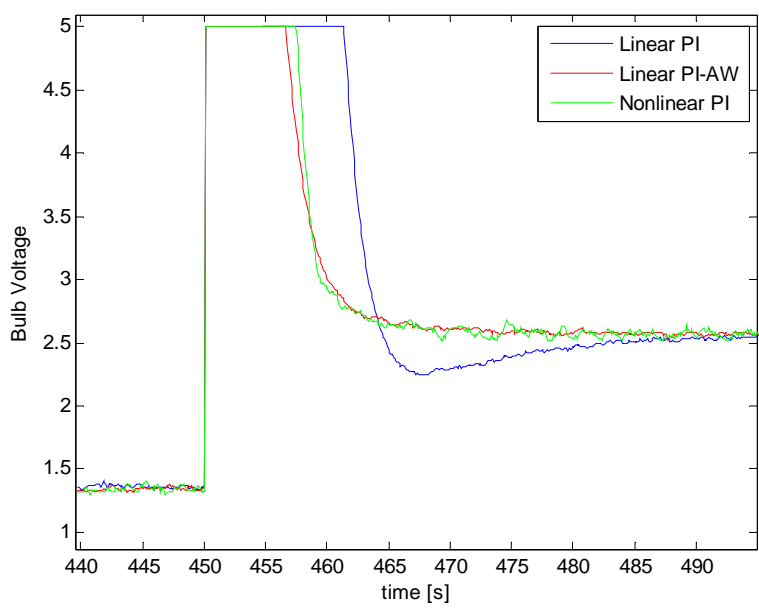

Figure 4. Control quality comparison - control signal

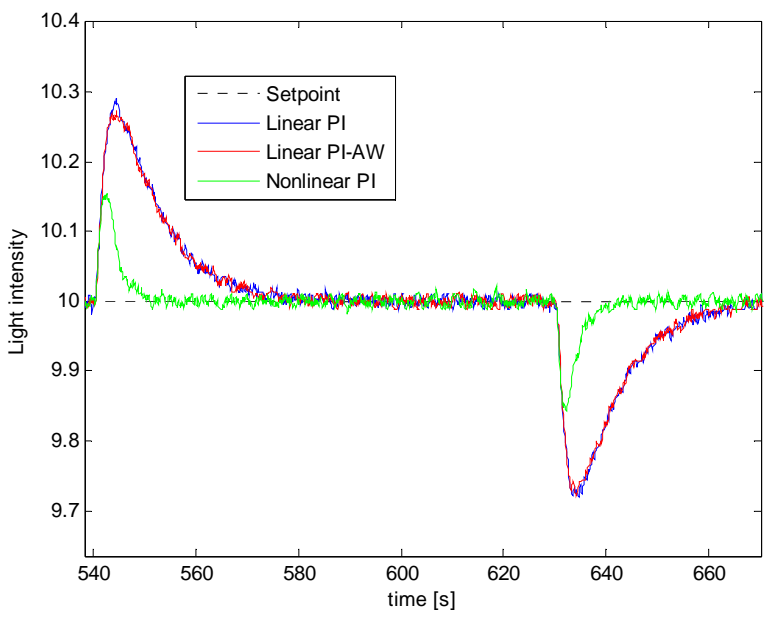

Figure 5. Control quality comparison - system output

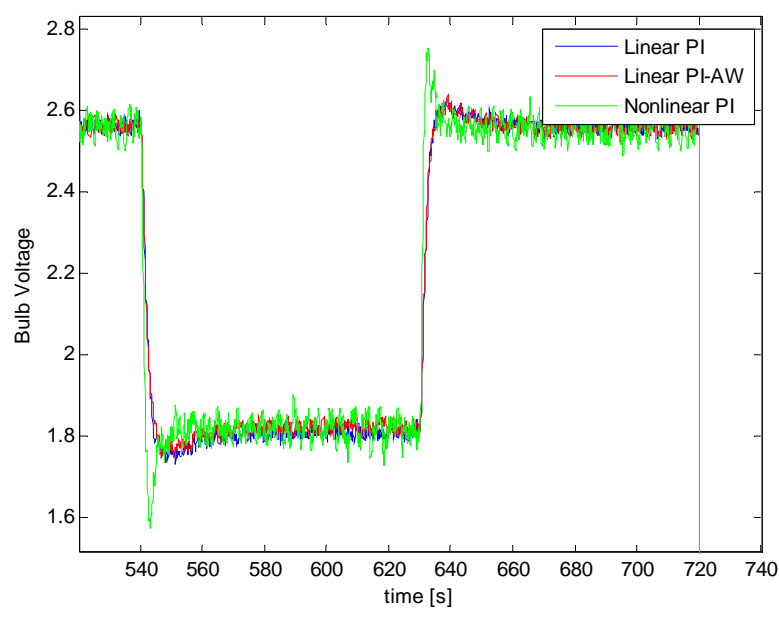

Figure 6. Control quality comparison - control signal 


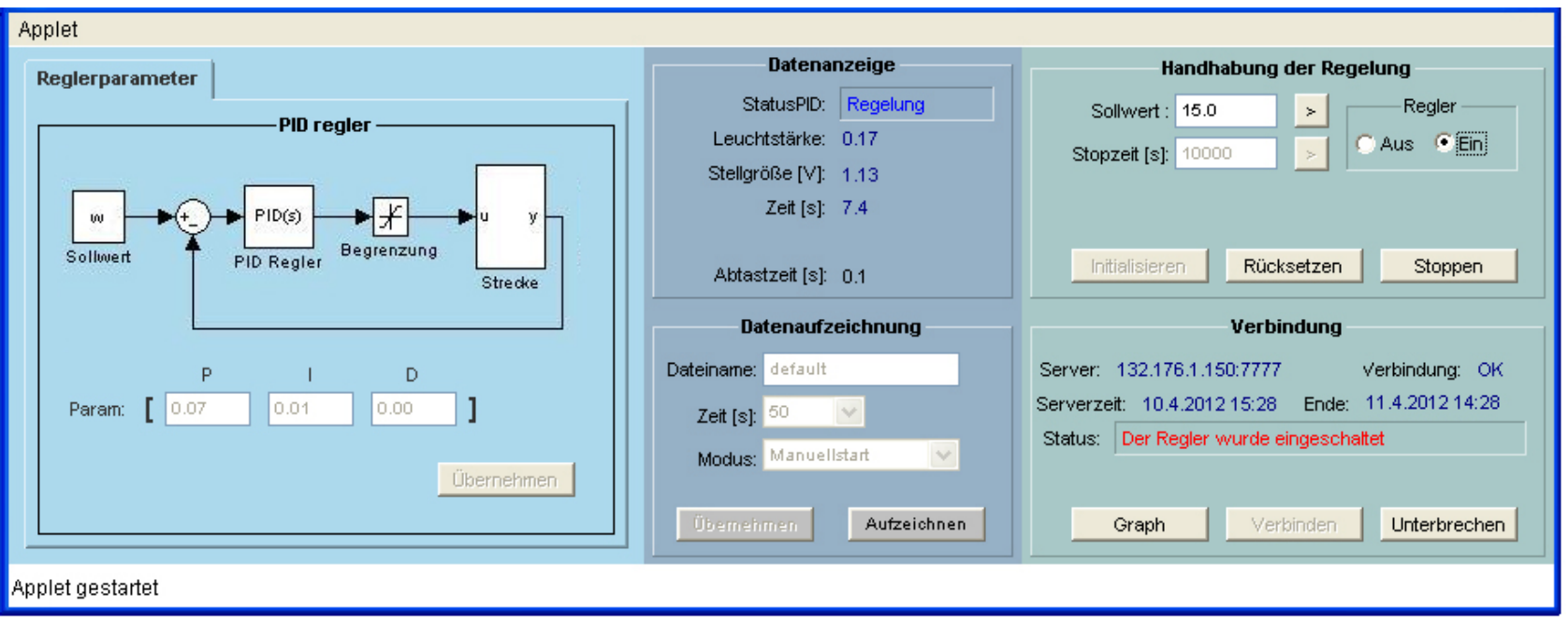

Figure 7. JAVA-Applet for control of the thermo-optical plant

\section{REFERENCES}

[1] Balestrino, A.; Caiti, A.; Crisostomi, E.; , "From Remote Experiments to Web-Based Learning Objects: An Advanced Telelaboratory for Robotics and Control Systems," Industrial Electronics, IEEE Transactions on , vol.56, no.12, pp.4817-4825, Dec. 2009. http://dx.doi.org/10.1109/TIE.2008.2006941

[2] Bistak, P.; "Matlab and Java based virtual and remote laboratories for control engineering," Control and Automation, 2009. MED '09. 17th Mediterranean Conference on , vol., no., pp.1439-1444, 2426 June 2009.

[3] Bisták, P.: 3D Visualization of Dynamical Systems for Learning Purposes. 10th Int. Conference ICL, Hasselt, 2010.

[4] Bisták, P. - Folvarčík, P.: Remote Laboratory Java Server Based on JACOB Project. In: International Journal of Online Engineering. - ISSN 1861-2121. - Vol. 7, No. 1 (2011), s. 33-36

[5] G. Farias, K.-E. Arzén, A. Cervin, S. Dormido, F. Esquembre: "Teaching Embedded Control Systems". Int. J. Engineering Education, 2010, 938-949.

[6] Gabriel, J.; Restivo, M.T.; , "Hands-on using on-line engineering: The trend to better solutions," E-Learning in Industrial Electronics, 2009. ICELIE '09. 3rd IEEE International Conference on , vol., no., pp.64-68, 3-5 Nov. 2009.

[7] Grimstad, B.: Studies in static output feedback control. NTNU Trondheim, 2009.

[8] Gomes, L.; Bogosyan, S.; , "Current Trends in Remote Laboratories," Industrial Electronics, IEEE Transactions on, vol.56, no.12, pp.4744-4756, Dec. 2009 http://dx.doi.org/10.1109/TIE.2009. $\underline{2033293}$

[9] Jáno, M. - Žáková, K.: SciLab Based Remote Control of ThermoOptical Plant. In: International Journal of Online Engineering. ISSN 1861-2121. - Vol. 7, No. 4 (2011), s. 10-15

[10] A Leva, F Donida: Multifunctional Remote Laboratory for Education in Automatic Control: The CrAutoLab Experience. IEEE Transactions on Industrial Electronics, 2008. http://dx.doi.org/10.1109/TIE.2008.922590

[11] P. Martí, M. Velasco, J. M. Fuertes, A. Camacho, G. Buttazzo. Design of an embedded control system laboratory experiment. "IEEE transactions on industrial electronics", 2010, vol. 57, 10, p. 3297-3307. http://dx.doi.org/10.1109/TIE.2010.2040559

[12] Masár, I., Bahník, P.: Design of an easy re-configurable remote laboratory, 14th International Conference on Interactive Collaborative Learning ICL, Pieštany, Slovakia, September 2011

[13] Ramos-Paja, C.A.; Scarpetta, J.M.R.; Martinez-Salamero, L.; , "Integrated Learning Platform for Internet-Based ControlEngineering Education," Industrial Electronics, IEEE Transactions on , vol.57, no.10, pp.3284-3296, Oct. 2010. http://dx.doi.org/ 10.1109/TIE.2010.2043033

[14] Restivo, M.T.; Mendes, J.; Lopes, A.M.; Silva, C.M.; Chouzal, F.; "A Remote Laboratory in Engineering Measurement," Industrial Electronics, IEEE Transactions on , vol.56, 12, pp.4836-4843, Dec. 2009 http://dx.doi.org/10.1109/TIE.2008.2011479

[15] Žáková, K. - Kohút, M.: Matlab Based Remote Control of Thermo-Optical Plant. In: International Journal of Online Engineering. - ISSN 1861-2121. - Vol. 5, Special Issue (2009), s. 27-29

[16] Žilka, V. - Bisták, P. - Kurčík, P.: Hydraulic Plant Remote Laboratory. In: International Journal of Online Engineering. ISSN 1861-2121. - Vol. 4, Special Issue (2008)

\section{AUTHORS}

P. Ťapák is with the Institute of Control and Industrial Informatics, Faculty of Electrical Engineering and Information Technology, Slovak University of Technology in Bratislava, Slovakia, (e-mail: peter.tapak@stuba.sk).

M. Huba received the MSc. and $\mathrm{PhD}$. Degrees in Technical Cybernetics from Slovak University of Technology in Bratislava in 1974 and 1982, respectively. Since 1989 he was a Senior Lecture and Head of the Control Theory Group of the Institute of Control and Industrial Informatics and from 2008 Full Professor at the Faculty of Electrical Engineering and Information Technology. In 1996 he initiated establishment of the university Distance Education Centre and worked as itts director up to 2008. Since 2008 he was also active in research at the FernUniversität Hagen, Germany, where he now continues as the Mercator visiting professor. He is author and co-author of more than 200 papers in journals and proceedings of international conferences and 20 monographs on Constrained, Nonlinear and Remote Control and about eLearning.

I. Masár is with the Control Engineering Group, Faculty of Mathematics and Computer Science, FernUniversität in Hagen, D-58093 Germany (e-mail: ivan.masar@fernuni-hagen.de).

This article is an extended and modified version of a paper presented at the International Conference on Interactive Collaborative Learning (ICL2012), held 26 - 28 September 2012, in Villach, Austria. Received 30 November 2012. Published as resubmitted by the authors 24 January 2013 